\title{
Paul R. Hanson, Contesting the French Revolution
}

Jean-Pierre Gross

\section{(2) OpenEdition \\ 1 Journals}

\section{Édition électronique}

URL : https://journals.openedition.org/ahrf/11734

DOI : 10.4000/ahrf.11734

ISSN : 1952-403X

Éditeur :

Armand Colin, Société des études robespierristes

\section{Édition imprimée}

Date de publication : 1 septembre 2010

Pagination : 197-200

ISBN : 978-2-200-92633-5

ISSN : 0003-4436

Référence électronique

Jean-Pierre Gross, "Paul R. Hanson, Contesting the French Revolution », Annales historiques de la Révolution française [En ligne], 361 | juillet-septembre 2010, mis en ligne le 22 mars 2011, consulté le 23 avril 2022. URL : http://journals.openedition.org/ahrf/11734; DOI : https://doi.org/10.4000/ahrf. 11734

Ce document a été généré automatiquement le 23 avril 2022.

Tous droits réservés 


\title{
Paul R. Hanson, Contesting the French Revolution
}

\author{
Jean-Pierre Gross
}

\section{RÉFÉRENCE}

Paul R. Hanson, Contesting the French Revolution, Chichester, Wiley-Blackwell, 2009, 229 p., ISBN 978-1-4051-6084-1, 34.95 \$.

1 Paul Hanson, qui nous a récemment livré deux ouvrages d'exception, The Jacobin Republic Under Fire (Pennsylvania University, 2003), histoire de l'insurrection fédéraliste de 1793, et un Historical Dictionary de la période révolutionnaire (Lanham, 2004), nous offre ici un bilan très complet des ouvrages les plus récents consacrés à la Révolution française, essentiellement en langue anglaise. Son livre adopte une structure thématique assez représentative des sujets de prédilection des auteurs angloaméricains, depuis la question des origines de la Révolution jusqu'à son héritage contesté (d'où le titre), en se concentrant sur la critique révisionniste de l'analyse sociale marxiste, la prise en ligne de compte de la sphère publique habermasienne, la dynamique des droits de l'homme, la lutte antiféodale. Nous apprenons ainsi qu'un renouveau de la thèse marxiste classique est inscrit à l'ordre du jour, avec le récent ouvrage de Henry Heller sur The Bourgeois Revolution in France, 1789-1815 (New York, 2006). Le terrain ayant été déblayé par l'étude exhaustive du contenu des cahiers de doléances, publiée en 1998 par John Markoff et Gilbert Shapiro, d'où il ressort qu'une véritable révolution antiseigneuriale se préparait dans les campagnes françaises, dont la Grande Peur constitue le prologue et la législation sociale de la Convention montagnarde l'aboutissement. L'abolition de la féodalité est également le sujet de l'important ouvrage de Michael Fitzsimmons sur la nuit du 4 août 1789 (The Night the old Regime Ended, Pennsylvania, 2003). Analyse qui fait apparaître l'émergence d'un « consensus fonctionnel » qui anima les travaux de l'Assemblée constituante pendant le reste de son mandat et qui mina les structures de l'Ancien Régime. 
2 D'un intérêt particulier s'avère le chapitre 3 du livre de Hanson sur la Déclaration des droits de l'homme et du citoyen, à la suite de l'étude stimulante de Lynn Hunt, Inventing Human Rights : a History (New York, 2007), qui met en évidence «la logique implacable des droits ", destinée à mobiliser tant l'opinion populaire que celle des élites. Logique qui est le reflet, selon Hunt, du grand mouvement d'émancipation qui gagne les esprits, se traduisant par une prise de conscience progressive des droits naturels applicables à tous sans exception, et entrainant toute une série de mesures émancipatrices : octroi de l'état civil aux minorités religieuses, aux protestants d'abord (édit de 1787), aux juifs ensuite, proclamés libres et égaux par l'Assemblée constituante, aux compagnons affranchis de leurs maitres lors de l'abolition des corporations en 1791, aux paysans libérés du poids des redevances seigneuriales, aux domestiques de sexe masculin qui reçoivent le suffrage en 1793, bientôt aux esclaves noirs promis à la liberté dans les colonies françaises. Prise de conscience à vocation universelle, qui rend envisageable, voire incontournable à terme, l'attribution de tels droits civils égaux aux femmes.

Hanson consacre son chapitre 4 à l'échec de la monarchie constitutionnelle en France. Comment un roi de droit divin, formé selon les principes de l'absolutisme royal, pouvait-il en son âme et conscience entériner des décrets qui dépossédaient de leurs droits séculaires clergé et noblesse, et affirmaient, sans même évoquer la personne royale, que la souveraineté était indivisible et résidait dans la nation? Un roi qui tenait son autorité de Dieu pouvait-il régner au nom de la loi, une loi à laquelle il serait désormais soumis comme tout autre citoyen du royaume? Le roi et la reine, entourés de leurs courtisans, ont-ils tout simplement refusé de jouer le jeu et se plier à la nouvelle structure constitutionnelle? Ou les députés les plus radicaux de l'Assemblée ont-ils créé un carcan si contraignant pour le pouvoir royal qu'aucun monarque n'aurait pu s'y soumettre? Telles sont les questions qui se posent aujourd'hui aux chercheurs qui se penchent sur la brève histoire de la «monarchie limitée » de modèle français. Ce débat mérite d'être examiné à la lumière du livre de Timothy Tackett sur la fuite à Varennes (When the King took Flight, Harvard, 2003), ainsi que du texte récemment publié par Jean-Christian Petitfils et Jacques de Saint-Victor, la "Déclaration du Roi adressée à tous les Français à sa sortie de Paris ", du 20 juin 1791 (Testaments et manifestes de Louis XVI, Paris, Équateurs, 2009). Le roi ne s'était-il rallié aux conquêtes démocratiques que forcé et contraint? Ce texte révèle au contraire un Louis XVI ayant tourné le dos à l'absolutisme, qui ne se présente plus comme le roi de France mais comme celui des Français, dévoué à ses concitoyens et soucieux de régner suivant les lois : un roi qui se serait transformé, certes trop tard, en véritable monarque constitutionnel.

En ce qui concerne la République, Hanson a des pages intéressantes inspirées des travaux de Malcolm Crook (Elections in the French Revolution, Cambridge, 1996) et de Peter McPhee (Living the French Revolution, 1789-1799, New York, 2006), qui ont mis en évidence le succès des campagnes électorales communautaires dans le ralliement des populations à l'idée républicaine et leur apprentissage de la démocratie. Quant aux colonies et à l'esclavage aux Antilles, il souligne tout l'intérêt des ouvrages de Laurent Dubois (Avengers of the New World, Harvard 2004 ; A Colony of Citizens : Revolution and Slave Emancipation in the French Caribbean, 1787-1804, Chapel Hill, 2004) et de J. D. Garrigus (Before Haiti : Race and Citizenship in French Saint-Domingue, New York, 2006). Sur la vertu en politique à l'époque des Lumières françaises, on aura intérêt à consulter les études de M. Linton: The Politics of Virtue (New York, 2001), et "Fatal Friendships", (French 
Historical Studies, 31, hiver 2008, p. 51-76). Linton y réfute la thèse de François Furet selon laquelle les jacobins auraient inventé l'idée de vertu, tout en soulignant que la Terreur a eu pour effet de discréditer cet idéal dans la politique, tout au moins en France et en Angleterre.

5 Outre-Atlantique, le Directoire connaît un regain d'intérêt grâce aux thèses diamétralement opposées de deux chercheurs américains, James Livesey et Howard Brown. Le premier s'est penché sur le rôle à ses yeux crucial qu'aurait joué le Directoire, malgré son instabilité chronique, qui rendit possible l'avènement de Napoléon Bonaparte, en posant les fondations de la démocratie en Europe (J. Livesey, Making Democracy in the French Revolution, Harvard, 2001). Livesey aboutit en effet à la surprenante conclusion qu'entre 1795 et 1800, un nouveau républicanisme démocratique fut élaboré, alors que jacobins et sans-culottes avaient échoué dans leur tentative d'établir une société politique où les droits universels n'entraveraient pas les libertés individuelles. Après Thermidor, les républicains au cœur du pouvoir directorial, tels Constant, Daunou et François de Neufchâteau, ont réussi à jeter les bases d'un tel régime : contraste frappant entre la démocratie libérale du Directoire et l'égalitarisme démocratique des jacobins. Howard Brown souligne au contraire l'insuccès criant de la démocratie libérale du Directoire, qu'il attribue à la violence endémique, aux formes de justice contestables et au recours réitéré à la répression musclée. Les vingt-six districts militaires lui fournirent l'instrument de cette répression, qui fut accueillie favorablement par une population écœurée par le désordre civil. L'État sécuritaire mis en place aurait ainsi balisé la voie au régime de Napoléon après 1802. Conclusions nuancées, comme on le sait, en France, par Bernard Gainot, Michel Biard et Pascal Dupuy.

6 Hanson consacre tout un chapitre à Napoléon. Il souscrit au consensus entre historiens de nos jours, qui veut que la Révolution ait fondé la démocratie moderne, et il ne saurait donc admettre que l'homme qui se proclama empereur ait pu construire son empire sur cette fondation. Même si les carrières furent ouvertes aux talents, les libertés furent victimes de la censure et de la coercition; nonobstant le Code Napoléon qui établit une égalité légale, toujours en vigueur aujourd'hui, les femmes furent subordonnées aux hommes dans le cadre de la famille patriarcale, tandis que noirs et gens de couleur ont souffert du rétablissement de l'esclavage dans les colonies françaises. Certes, le 18 Brumaire, coup de force d'un général putschiste contre les deux chambres, demeure un mythe, dû au charisme de son auteur. Pourtant, la démocratie était déjà compromise sous le Directoire, et l'État sécuritaire était déjà en place. Le régime consulaire est une dictature progressive, qui va de plébiscite en plébiscite, le gouvernement "parlementaire " étant basé sur les nominations et non sur les élections. Sans doute, le système électoral était censé à l'époque produire l'unanimité. Mais la France ne s'est jamais entièrement remise de telles compromissions, l'abandon de l'autorité légale, associé à l'apparition d'un leader providentiel, y ayant instauré la tradition toujours vivace d'un exécutif puissant, la méfiance du pluralisme et le mépris, même voilé, du parlementarisme! Le paradoxe de Napoléon, selon Steven Englund, c'est qu'en pur produit de la Révolution, il l'a terminée et trahie tout à la fois (Napoleon : a Political Life, Harvard, 2004).

7 La réalisation principale de l'Empire a été une centralisation étatique forte et structurée, plus efficace et moderne que par le passé (M. Lyons, Napoleon Bonaparte and the Legacy of the French Revolution, New York, 1994). Grâce à ses guerres continentales, 
Napoléon a réussi à exporter à l'étranger nombre d'idéaux révolutionnaires qu'il a trahis en France. Mais ces guerres ont semé la mort à une échelle catastrophique : entre 1803 et 1814, la France à elle seule a connu des pertes de plus d'un million (bien plus que les pertes dues à la Terreur et la Vendée combinées). Il n'empêche que la population française est passée de 26 millions en 1789 à 30 millions en 1815 .

La prise en considération du nombre de victimes de l'épopée militaire amène Hanson à examiner l'effet de la violence révolutionnaire, qu'il s'agisse des massacres de septembre ou de la répression sous la Terreur. La violence a-t-elle été « le moteur de la Révolution", comme l'affirmait Simon Schama en 1989 ? Tant Lynn Hunt que Jack Censer ont exprimé l'opinion en 2005, dans l'American Historical Review, que les députés bourgeois qui ont fait la Révolution dépendaient du soutien populaire, donc de la violence populaire qui a poussé la Révolution en avant. Hanson partage plutôt l'avis de David Andress, qui estime que la Terreur a détruit ce qu'elle tendait à préserver (The Terror : the Merciless War for Freedom in Revolutionary France, New York, 2005). Même si la Terreur demeura « légale » malgré ses excès, comme l'a fait observer Alan Forrest, elle a mis en place une répression étatique, militarisée ensuite par le Directoire. Hanson demeure convaincu que la " politique participative ", et non la violence, a été le moteur de la Révolution. Elle s'estompe sous l'autoritarisme libéral du Directoire et disparaît pour de bon sous Bonaparte. La violence se poursuivra, sous diverses formes, notamment celle de la faim et de la privation : le droit à la subsistance engendre les dernières journées de germinal et prairial an III, mais continuera de nos jours à solliciter les gouvernements des pays du Tiers Monde.

9 C'est l'un des aspects de l'héritage de la Révolution évoqué dans le dernier chapitre du livre de Hanson. Quels en sont les autres? Sans conteste, aux yeux de Peter McPhee, le fait social le plus marquant de la Révolution française a été l'abolition des redevances et obligations seigneuriales: la société paysanne en est sortie transformée (The French Revolution, 1789-1799, Oxford, 2002). C'est dire l'importance de la nuit du 4 août 1789 mais aussi de la législation sociale de juin-juillet 1793, qui en a apporté le parachèvement. Le fait politique le plus marquant? Indiscutablement, la naissance de la République. La Révolution une révolution bourgeoise? Non pas au sens où l'entendait Marx, malgré les efforts déployés par Henry Heller pour ressusciter cette interprétation. Mais Hanson n'est pas convaincu non plus par les arguments de Sarah Maza, tendant à démontrer que la bourgeoisie n'est rien de plus qu'un mythe (The Myth of the French Bourgeoisie: an Essay on the Social Imaginary, 1750-1850, Harvard, 2003). Au bout du compte, comme l'affirmait Robert Darnton en 1989 dans la New York Review of Books, la Révolution a créé un nouveau sens de «possibilité illimitée » en donnant aux gens ordinaires la conviction qu'en travaillant ensemble ils pouvaient changer le monde.

Précisons enfin qu'une ample bibliographie complète ce bilan et témoigne de la richesse de la contribution des chercheurs anglo-américains à l'historiographie révolutionnaire: bibliographie dans laquelle les chercheurs étrangers, notamment français, sont également à l'honneur. 